\title{
Investigation on the Mental Health Status and Risk Factors Among Chinese Overseas Students Under COVID-19 Outbreak
}

\author{
Xiao Chunfeng \\ Capital Medical University \\ Luan Shuxin \\ Jilin University First Hospital \\ Kang Lirui \\ Jilin University First Hospital \\ Yuan Jingjing \\ Jilin University First Hospital \\ Liu Chang \\ Jilin University First Hospital
}

Cong Anan ( 18946215543@163.com )

Jilin University First Hospital https://orcid.org/0000-0001-8884-2808

Research

Keywords: COVID-19, Chinese overseas students, Mental health

Posted Date: July 6th, 2020

DOI: https://doi.org/10.21203/rs.3.rs-35535/v1

License: (9) This work is licensed under a Creative Commons Attribution 4.0 International License. Read Full License 


\section{Abstract}

\section{Background}

Corona Virus Disease (COVID-19) caused by SARS-CoV-2 had caused a global pandemic. According to incomplete statistics, at least 400,000 of Chinese overseas students were now staying abroad during the COVID-19 epidemic. Under the condition of extensive isolation, the social support system was also impacted, all this will lead to various kinds of psychological problems. However, there are no studies on the psychological problems of Chinese overseas students during the epidemic at home and abroad.

\section{Objectives}

To investigate the mental health status and its risk factors among Chinese overseas students during the COVID-19 pandemic.

\section{Methods}

We conducted a cross-sectional survey based on structured questionnaire through various social platforms (WeChat, QQ, etc.). The contents of the structured questionnaire included: demographic characteristics, 9-item Patient Health Questionnaire (PHQ-9), Generalized Anxiety Disorder 7-item Scale (GAD-7) and 15-item Patient Health Questionnaire (PHQ-15).

\section{Results}

$\nabla$ The incidence rates of depression, anxiety and physical symptoms were $60.3 \%, 53.2 \%$ and $83.3 \%$, respectively. $\otimes$ There were significant statistical differences in the incidence rates of depression, anxiety and physical symptoms between different genders (depression: $x^{2}=148.94, P=0.000$; anxiety: $x^{2}=129.45, P=0.000$; physical symptoms: $x^{2}=62.73, P=0.000$ ). Significant statistical differences were also found in the incidence rates of depression and anxiety among different education levels (depression: $x^{2}=10.82, P=0.013$; anxiety: $x^{2}=9.09, P=0.028$ ). Additionally, there were significant statistical differences in the incidence rates of depression $\left(x^{2}=12.77, P=0.005\right)$ among different ages, and time of daily attention to epidemic-related information were closely associated with physical symptoms $\left(x^{2}=12.14, P=0.007\right)$. LLogistic regression analysis showed that the female have a higher risk of developing depression [OR=0.017, 95\% Cl: 0.008 0.037, $P=0.000]$, anxiety [OR=0.024, 95\% Cl: $0.011 \sim 0.051, P=0.000]$ and physical symptoms [OR=0.018, 95\% Cl: $0.004 \sim 0.078, P=0.000]$, and time of daily attention to epidemic-related information was positively associated with the level of physical symptoms [OR=0.610,95\% $\mathrm{Cl}$ : $0.415 \sim 0.895, P=0.012]$.

\section{Conclusion}

During the COVID-19 epidemic, Chinese overseas students were highly susceptible to a series of psychological and mental problems, including depression, anxiety and physical symptoms, and have a relatively higher risk than other populations. The purpose of this study is to call on relevant departments to pay attention to the psychological problems of this special group and propose effective prevention and control measures to ensure the mental health of the masses during the epidemic and promote the scientific development of mental health work.

\section{Introduction}

According to the survey, the total number of Chinese students studying abroad was about 713,000. According to incomplete statistics, during the COVID-19 epidemic, about $40 \%$ of the students from the two major overseas study countries of the UK and the US returned to China, at least 400,000 of them were now staying abroad. However, due to the inability to return home, the family support system of overseas students couldn't play its corresponding role, at the same time, they faced pressure from study, life and other aspects. Under the condition of extensive isolation, the social support system was also impacted, all this would lead to various kinds of psychological problems. However, there were no studies on the psychological problems of Chinese overseas students during the epidemic at home and abroad. The purpose of this study was to understand the psychological status and related somatization symptoms of Chinese overseas students during the epidemic, and to provide theoretical basis for the implementation of mental health education and psychological intervention measures. 


\section{Participants And Methods}

\subsection{Participants}

From 18 May to 21 May 2020, snowball sampling was used to conduct an online questionnaire survey on Chinese overseas students during the COVID-19 epidemic. A total of 268 questionnaires were collected, 252 of them were valid, and the effective response rate was $94 \%(252 / 268)$.

\subsection{Methods}

2.2.1 Research Tools: (1) General Information Questionnaire: including gender, age, current country, education level, specialty, time of daily attention to COVID-19 related information, and whether people around you have heard of COVID-19 infection. (2) 9 Patient Health Questionnaire (PHQ-9): This scale is recommended by the World Health Organization as a preliminary screening and assessment of the severity of depressive disorders, and has good reliability and validity. No, mild, moderate, moderate and severe depression are rated according to the scores $0 \sim 4,5 \sim 9,10 \sim 14,15 \sim 19,20 \sim 27^{[1]}$. $₫ 3 \otimes$ Generalized Anxiety Disorder Scale (GAD-7) : This scale is a tool recommended by DSM-5 (Diagnostic and Statistical Manual of Mental Disorders, 5th Edition) for early screening of GAD in various populations with good reliability and validity. No, mild, moderate, and severe anxiety disorders are assessed according to scores 0 4, 5 9, 10 14, and 15 21 ${ }^{[2]}$. 4 4هPatient Health Questionnaire (PHQ-15) : This scale is used to screen mental disorders mainly manifested by physical symptoms and assess their severity with good reliability and validity. According to the score $0 \sim 4,5 \sim 9,10 \sim 14,15 \sim$ are classified into very light, light, medium and severe somatic problems ${ }^{[3]}$.

2.2.2 Survey method: Two investigators introduced the purpose and confidentiality of the survey to Chinese overseas students by sending questionnaires to WeChat group and QQ group, etc. Respondents voluntarily filled in the questionnaire according to their actual situation. At the end of the survey, these questionnaires were uniformly reviewed and included into valid questionnaires for statistical analysis.

2.2.3 Statistical processing: We imported data into Excel and used SPSS26.0 for data processing and analysis. The difference in detection rate of depression, anxiety and somatization symptoms among groups was determined by $x^{2}$ test. With the presence of depression, anxiety and somatization symptoms as the dependent variables, the significant independent variables were analyzed by univariate Logistic regression, the influencing factors of the mental health status of overseas students under the epidemic situation were analyzed. $P<0.05$ was considered as statistically significant.

\section{Results}

\subsection{General Information}

Among the 252 overseas students, 102 were male (40.5\%) and 150 were female (59.5\%). 2 (0.8\%) were younger than 18 years old, 160 (63.5\%) were between 18 and 25 years old, 70 (27.8\%) were between 26 and 30 years old, and 20 (7.9\%) were older than 30 years old. In North America (78, 30.1\%), Oceania (12, 4.8\%), Europeans (54, 21.4\%), And Asians (108, 42.9\%); There were 2 (0.8\%) with high school education, $93(36.9 \%)$ were undergraduate students, $110(43.7 \%)$ were postgraduate students and 47 (18.7\%) were doctoral students. There were 33 (13.1\%) medical students and 219 (86.9\%) non-medical students.

\subsection{Detection rate and univariate analysis of depression, anxiety and somatization symptoms}

Among all the respondents, the detection rate of depression was $60.3 \%, 77$ (50.7\%) of them were mildly depressed, 53 (34.9\%) were moderately depressed, $16(10.5 \%)$ were moderate to severe depression and $6(3.9 \%)$ were severely depressed. The detection rate of anxiety was $53.2 \%$, among which $88(65.7 \%)$ had mild anxiety, $37(27.6 \%)$ had moderate anxiety and $9(6.7 \%)$ had severe anxiety. The detection rate of somatization symptoms was $83.3 \%$, among which 87 (41.4\%) had very mild somatization symptoms, 75 (35.7\%) had mild somatization symptoms, 32 (15.2\%) had moderate somatization symptoms, and 16 (7.6\%) had severe somatization symptoms. Meanwhile, we observed gender differences in the PHQ-9, GAD-7 and PHQ-15, education level 
was an influential factor for depression and anxiety, age was an influential factor for depression, and daily attention to epidemic information was an influential factor for somatization symptoms (Table 1).

3.3 Multivariate Logistic regression analysis

The results of binary Logistic regression analysis showed that female students $(P<0.05)$ were the risk factors for depression, anxiety and somatization symptoms of Chinese overseas students under the COVID-19 pandemic. Meanwhile, the longer time to pay attention to relevant information of the epidemic every day, the greater the possibility of somatization symptoms $(P<0.05)$. However, education level and age were not significantly associated with depression and anxiety $(P>0.05)($ Table 2). 
Table 1

General information and detection rate of depression, anxiety and somatization symptoms $(\mathrm{N}, \%)$

\begin{tabular}{|c|c|c|c|c|c|c|c|c|c|c|}
\hline \multirow[t]{2}{*}{$\begin{array}{l}\text { General } \\
\text { information }\end{array}$} & \multirow[t]{2}{*}{ number } & \multicolumn{3}{|c|}{ depression(PHQ-9 > 4) } & \multicolumn{3}{|c|}{ anxiety(GAD-7 > 4) } & \multicolumn{3}{|c|}{$\begin{array}{l}\text { somatization } \\
\text { symptoms(PHQ-15 }>0)\end{array}$} \\
\hline & & occurrence & $x^{2}$ & $P$ & occurrence & $x^{2}$ & $P$ & occurrence & $x^{2}$ & $P$ \\
\hline gender & & & 148.94 & 0.000 & & 129.45 & 0.000 & & 62.73 & 0.000 \\
\hline male & 102 & $15(14.7)$ & & & $10(9.8)$ & & & $62(60.8)$ & & \\
\hline female & 150 & 137(91.3) & & & $124(82.7)$ & & & 148(98.7) & & \\
\hline age & & & 12.77 & 0.005 & & 4.83 & 0.185 & & 1.23 & 0.746 \\
\hline$<18$ years old & 2 & $0(0)$ & & & $0(0)$ & & & $2(100.0)$ & & \\
\hline $\begin{array}{l}18 \sim 25 \text { years } \\
\text { old }\end{array}$ & 160 & $98(61.3)$ & & & $85(53.1)$ & & & 133(83.1) & & \\
\hline $\begin{array}{l}26 \sim 30 \text { years } \\
\text { old }\end{array}$ & 70 & $36(51.4)$ & & & $35(50.0)$ & & & $57(81.4)$ & & \\
\hline$>30$ years old & 20 & 18(90.0) & & & 14(70.0) & & & 18(90.0) & & \\
\hline $\begin{array}{l}\text { Geographical } \\
\text { location }\end{array}$ & & & 3.49 & 0.322 & & 4.32 & 0.229 & & 6.37 & 0.095 \\
\hline $\begin{array}{l}\text { In North } \\
\text { America }\end{array}$ & 78 & $52(66.7)$ & & & $47(60.3)$ & & & $67(85.9)$ & & \\
\hline Oceania & 12 & $6(50.0)$ & & & $8(66.7)$ & & & 11(91.7) & & \\
\hline The European & 54 & $28(51.9)$ & & & $24(44.4)$ & & & $39(72.2)$ & & \\
\hline Asia & 108 & $66(61.1)$ & & & $55(50.9)$ & & & 93(86.1) & & \\
\hline $\begin{array}{l}\text { Education } \\
\text { level }\end{array}$ & & & 10.82 & 0.013 & & 9.09 & 0.028 & & 0.43 & 0.934 \\
\hline High school & 2 & $1(50.0)$ & & & $1(50.0)$ & & & $2(100.0)$ & & \\
\hline $\begin{array}{l}\text { Undergraduate } \\
\text { course }\end{array}$ & 93 & $44(47.3)$ & & & $38(40.9)$ & & & $77(82.8)$ & & \\
\hline $\begin{array}{l}\text { Master } \\
\text { candidate }\end{array}$ & 110 & 76(69.1) & & & $67(60.9)$ & & & $92(83.6)$ & & \\
\hline $\begin{array}{l}\text { Doctoral } \\
\text { candidate }\end{array}$ & 47 & $31(66.0)$ & & & 28(59.6) & & & $39(83.0)$ & & \\
\hline professional & & & 0.00 & 0.971 & & 1.76 & 0.184 & & 0.06 & 0.802 \\
\hline medical & 33 & $20(60.6)$ & & & $14(42.4)$ & & & $28(84.8)$ & & \\
\hline $\begin{array}{l}\text { Non-medical } \\
\text { specialty }\end{array}$ & 219 & 132(60.3) & & & $120(54.8)$ & & & 182(83.1) & & \\
\hline $\begin{array}{l}\text { Follow the } \\
\text { epidemic } \\
\text { information } \\
\text { time/day }\end{array}$ & & & 0.80 & 0.850 & & 7.20 & 0.066 & & 12.14 & 0.007 \\
\hline$<1$ hour & 158 & $92(58.2)$ & & & $78(49.4)$ & & & 133(84.2) & & \\
\hline $1 \sim 2$ hours & 45 & $29(64.4)$ & & & $27(60.0)$ & & & $41(91.1)$ & & \\
\hline $2 \sim 4$ hours & 24 & $15(62.5)$ & & & 18(75.0) & & & $21(87.5)$ & & \\
\hline$>4$ hours & 25 & 16(64.0) & & & 11(44.0) & & & 15(60.0) & & \\
\hline
\end{tabular}




\begin{tabular}{|c|c|c|c|c|c|c|c|c|c|c|}
\hline \multirow[t]{2}{*}{$\begin{array}{l}\text { General } \\
\text { information }\end{array}$} & \multirow[t]{2}{*}{ number } & \multicolumn{3}{|c|}{ depression(PHQ-9 > 4) } & \multicolumn{3}{|c|}{ anxiety(GAD-7 > 4) } & \multicolumn{3}{|c|}{$\begin{array}{l}\text { somatization } \\
\text { symptoms(PHQ-15 }>0)\end{array}$} \\
\hline & & occurrence & $x^{2}$ & $P$ & occurrence & $x^{2}$ & $P$ & occurrence & $x^{2}$ & $P$ \\
\hline $\begin{array}{l}\text { Have you } \\
\text { heard that } \\
\text { someone } \\
\text { around you is } \\
\text { infected }\end{array}$ & & & 0.20 & 0.654 & & 3.74 & 0.053 & & 0.68 & 0.410 \\
\hline yes & 54 & $34(63.0)$ & & & $35(64.8)$ & & & $47(87.0)$ & & \\
\hline no & 198 & 118(59.6) & & & $99(50.0)$ & & & 163(82.3) & & \\
\hline
\end{tabular}

Table 2

Logistic regression analysis of depression, anxiety and somatization symptoms of overseas students

\begin{tabular}{|c|c|c|c|c|c|c|c|}
\hline & Factors affecting & $B$ & $S E$ & Wald & $O R$ & $P$ & $95 \% \mathrm{Cl}$ \\
\hline depression & gender & -4.079 & 0.405 & 101.257 & 0.017 & 0.000 & $\begin{array}{l}0.008 \sim \\
0.037\end{array}$ \\
\hline anxiety & gender & -3.749 & 0.399 & 88.292 & 0.024 & 0.000 & $\begin{array}{l}0.011 \sim \\
0.051\end{array}$ \\
\hline \multirow[t]{2}{*}{$\begin{array}{l}\text { somatization } \\
\text { symptoms }\end{array}$} & gender & -4.025 & 0.754 & 28.473 & 0.018 & 0.000 & $\begin{array}{l}0.004 \sim \\
0.078\end{array}$ \\
\hline & $\begin{array}{l}\text { Follow the epidemic information } \\
\text { time }\end{array}$ & -0.495 & 0.196 & 6.374 & 0.610 & 0.012 & $\begin{array}{l}0.415 \sim \\
0.895\end{array}$ \\
\hline
\end{tabular}

\section{Discussion}

According to the survey of 252 Chinese overseas students, the detection rate of depression, anxiety and somatization was as high as $60.3 \%, 53.2 \%$ and $83.3 \%$ respectively. Among them, 88 (65.7\%) had mild anxiety, $37(27.6 \%)$ had moderate anxiety, and 9 $(6.7 \%)$ had severe anxiety, which were significantly higher than the detection rate of mild anxiety $(21.3 \%)$, moderate anxiety $(2.7 \%)$ and severe anxiety $(0.9 \%)$ among domestic college students in the same period ${ }^{[4]}$. Meanwhile, the analysis found that the prevalence of depression, anxiety and somatization was significantly different between males and females, which was consistent with the results of a recent epidemiological survey conducted in China ${ }^{[5]}$. Wang et al. found that the risk of anxiety in women during the epidemic was 3.01 times that in men, which was different from the relevant results obtained in this study [OR $=0.017$, $95 \% \mathrm{Cl}(0.008-0.037), P=0.000]$. The reasons for the differences might be attributed to the differences in the survey subjects ${ }^{[6]}$. The analysis also found that the time to pay attention to epidemic information was significantly correlated with the detection rate of somatization symptoms. Huang et al. suggested that people who spent more than 3 hours a day following the development of the epidemic were more likely to develop generalized anxiety disorder ${ }^{[7]}$. It can be seen that the exposure of epidemic information or the significant correlation with a variety of mental and psychological problems requires special attention. Relevant departments should pay attention to the orientation of social media information and pay close attention to the psychological impact of media information on the public.

It should be noted that in the process of collecting the information of the subjects, two investigators received some inquiries from overseas Chinese students. Most of the consultants pointed out that they felt very anxious recently due to the impact of the epidemic, and the main purpose of the inquiries was to "find someone to talk", indicating that most of the Chinese overseas students were not willing to take the initiative to seek help. Based on the above situation, one thing to note that the lack of initiative to help motive might caused the increase of mental psychological problems and development new problems, the traditional "passive accepts" mental health services was not timely, effective, targeted for such people into necessary intervention, which might lead to more serious consequences. In addition, the above situation also explains the main reason for the small sample size of this study. In future studies, the sample size should be expanded on the basis of this study, and more natural demographic information should be statistically analyzed to accurately target more potential risk factors. 
The study found that Overseas students in China were highly susceptible to a series of mental and psychological problems during the COVID-19 epidemic, which was higher than other types of people during the same period, suggesting that the mental health support work for such groups is urgently needed. However, due to the limited evidence-based support provided by relevant literature and the unbalanced allocation of mental health service resources, the mental health work for overseas Chinese students has not received sufficient attention. This study is the first to investigate the mental and mental health status of Chinese overseas students during the COVID-19 epidemic, while promoting the scientific development of mental health during the epidemic, it is necessary to institute a mental health system to Chinese overseas students.

\section{Declarations}

Ethics approval and consent to participatenEthical Committee of the First Hospital of Jilin University $2020-361 \rrbracket$.

Consent for publication』Not applicable.

Availability of data and material[AIl data generated or analysed during this study are included in this published article.

Competing interest: The authors declare that they have no competing interests.

Funding Not applicable.

Authors' contributions $\square$ Cong Anan was a major contributor in writing the manuscript.; Xiao Chunfeng, Kang Lirui, Yuan Jingjing is responsible for data collection and processing; Luan Shuxin and Liu Chang are responsible for the topic selection and revision of the paper. All authors read and approved the final manuscript.

Acknowledgements: Thank you to Professor Zhang Jimin, visiting scholar from The College of William and Mary; Cui Ziwen, Eurasian University of Kumilov, Kazakhstan; Cong Pingping, visiting student of University of Western Ontario, Canada; Xin Zhao, Shimane University, Japan; Xinyi Zhang, Hongyi University, South Korea; Xinrui Wang, University of Sheffield, UK; Yuxuan Jin, University of Burgundy, France; Li Shiqi, Nanural State University, Chelyabinsk, Russia provided valuable support for the inclusion phase of the study.

\section{References}

1. Chen MM, Sheng L, Qu S. Diagnostic test of screening depressive disorders in general hospital with the Patient Health Questionnaire[J]. Chinese Mental Health Journal,2015, (4): 241-245.

2. Zhou YY, Bi YH, Lao LM, et al. Application of GAD-7 in population screening for generalized anxiety disorder. Chinese Journal of General Practitioners. 2018;17(9):735-7.

3. Qian J, Ren ZQ, Yu DH, et al. The value of the Patient Health Questionnaire-15(PHQ-15)for screening somatic symptonls in general hospital[J]. Chinese Mental Health Journal,2014, 028(003): 173-178.

4. Cao W, Fang Z, Hou G, et al. The psychological impact of the COVID-19 epidemic on college students in China[J]. Psychiatry Res. 2020;287:112934.

5. Ozdin S, Bayrak Ozdin S. Levels and predictors of anxiety, depression and health anxiety during COVID-19 pandemic in Turkish society: The importance of gender[J]. Int J Soc Psychiatry, 2020: 20764020927051.

6. Wang Y, Di Y, Ye J, et al. Study on the public psychological states and its related factors during the outbreak of coronavirus disease 2019 (COVID-19) in some regions of China[J]. Psychol Health Med, 2020: 1-10.

7. Huang Y, Zhao N. Generalized anxiety disorder, depressive symptoms and sleep quality during COVID-19 outbreak in China: a web-based cross-sectional survey[J]. Psychiatry Res. 2020;288:112954. 